\title{
A rare case of hemorrhagic mineralising angiopathy after trivial head trauma
}

\author{
Yareeda Sireesha $^{D_{1}}$, Niloufer Ali $^{2}$, Mathukumalli Lakshmi Neeharika ${ }^{\circledR}$, Meena Angamattu \\ Kanikannan $^{3}$ \\ ${ }^{1}$ Department of Neurology, Nizam's Institute of Medical Sciences, Hyderabad, Telangana, India, \\ ${ }^{2}$ Nizam's Institute of Medical Sciences, Hyderabad, India, Department of Pathology, Nizam's Institute \\ of Medical Sciences, Hyderabad, India
}

Corresponding author: Meena Angamattu Kanikannan; Email: mailforsiree@gmail.com

do) https://doi.org/10.17724/jicna.2019.141

Received: 31 Mar 2018

Accepted: 29 Dec 2019

\begin{abstract}
Infarction of the basal ganglia after minor head injury is a well described entity .'Mineralising angiopathy' is a term to describe mineralisation along the lenticulostriate vessels that predisposes infants to stroke,even after trivial head injury. The prognosis in these children is excellent. The supratentorial compartment is relatively mobile in comparision to the fixed infratentorial compartment offering greater shearing forces between the perforating vessels and the brain parenchyma following an acute trauma. The acute angulation of the lenticulostriate perforators is further responsible for its propensity of the basal ganglia for the insult. The current report is unique as it presents a young boy with hemorrhagic stroke in the basal ganglia after a trivial trauma and imaging findings suggestive of mineralising angiopathy.
\end{abstract}

Kewords: mineralising angiopathy, basal ganglia infarct, lenticulostriate vessels.

(C) Sireesha Y; licensee JICNA

\section{Introduction}

Infarction of the basal ganglia after minor head injury is a well-described entity. 'Mineralising angiopathy' is a term to describe mineralisation along the lenticulostriate vessels (LSV) and is usually seen after a trivial head injury with a presentation as acute stroke [1].The prognosis in these children is excellent. The supratentorial compartment is relatively mobile in comparision to the fixed infratentorial compartment, offering greater shearing forces between the perforating vessels and the brain parenchyma following an acute trauma [2]. The acute angulation of the lenticulostriate perforators is another postulate, suggesting the propensity of the basal ganglia for the insult [3]. In this case report, we present a young boy with hemorrhagic stroke in the basal ganglia after a trivial trauma and with imaging findings suggestive of mineralising angiopathy.

\section{Case description}

A nine-year-old boy presented with a history of trivial head injury over the left parietal area after a trivial fall while playing cricket. He had no loss of consciousness, nor bleeding from nose, mouth or ear. He did not sustain any external injuries. An hour later, he noticed sudden onset weakness of right upper and lower limb and deviation of angle of mouth to the left. His blood pressure when he was brought to the hospital was $110 / 70 \mathrm{mmHg}$. All his peripheral pulses were regular in volume and character and normal in rate and rhythm. Cardiac examination was normal. He had an upper motor neuron palsy of the right seventh nerve. The power was $0 / 5$ in the right upper and lower limb according to MRC (medical research council) grading, with extensor plantar reflex and brisk deep tendon reflexes on the right. The rest of the neurological examination was normal.

Investigations showed hemoglobin of $12.5 \mathrm{~g} / \mathrm{dL}$, a normal differential white blood cell count and platelets, and no evidence of coagulopathy. His vasculitic profile included the presence of titres in the serum antinuclear antibodies (ANAs), antibodies to extractable nuclear antigens (ENAs), anti-native DNA antibodies (anti-DNA), topoisomerase I antibodies (Scl-70), antibodies to cyclic citrullinated peptides (anti-CCP), rheumatoid factor (RA factor), C-ANCA (myeloperoxidase) and p-ANCA (proteinase 3) levels, which were normal. Serological markers, including both IgG and IgM antibodies against cytomegalovirus, toxo- 
plasma, rubella and herpes, were negative. He was negative for HIV (human immunodeficiency virus) and the Hepatitis B surface antigen test. An electrocardiogram (ECG) and a two-dimensional echocardiography (2D Echo) were normal. A metabolic work-up test, including serum calcium, phosphorus, magnesium, thyroid, parathormone and vitamin $\mathrm{D}$ levels, was normal. A sickling test was negative.

A computerised tomogram (CT) of the brain revealed hyperdensity in the left basal ganglia and a small speck of hyperdensity on the right (Figure 1). MRI (magnetic resonance imaging) confirmed the bleed in the left basal ganglia and showed no other parenchymal changes while the MRA (magnetic resonance angiogram) was normal. Possibilities considered were mineralising angiopathy with a hemorrhage in the left basal ganglia after a trivial trauma and an arteriovenous malformation. The patient was ad-

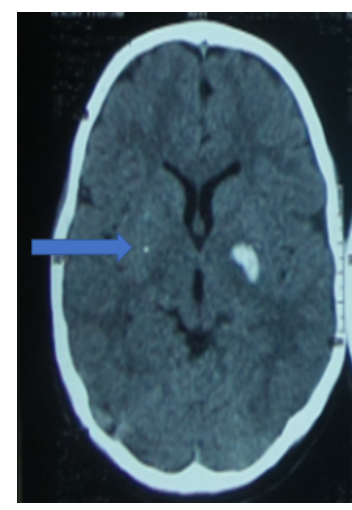

Figure $1 \mathrm{~A} \mathrm{CT}$ brain plain showing a comma-shaped hyperdensity in the left lentiform nucleus, suggestive of hemorrhage. A single dot of hyperdensity in the right basal ganglia is suggestive of a mineralised vessel.

vised physical therapy and was followed up. Over the next three months, his strength improved significantly. He was walking with a mild drag of the left foot that was barely noticeable and had a subtle weakness of hand grip. A CT scan of the brain was repeated that showed resolution of the bleed (Figure 2). A DSA (digital subtraction angiogram) showed as normal three months after the stroke and so excluded a vascular malformation. Thus, a final diagnosis of a hemorrhagic stroke caused by underlying mineralising angiopathy could be made.

\section{Discussion}

Lenticulostriate vasculopathy (LSV) is a well-known entity [4]. It descibes the hyperechoic vessels seen in the region of the basal ganglia or the thalamus. Such an entity is seen in less than two percent of all childhood strokes, particularly after minor trauma [1], [5]. The etiology of these LSVs is not clear. Cytomegaloviral infections can present as periventricular calcifications [6] and is suspected in patients with LSV of a higher grade (multiple branches and higher echogenicity) on a neurosonogram and is associated

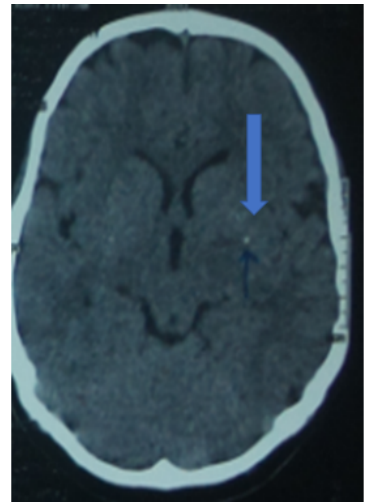

Figure 2 A CT brain plain axial section at the level of the midbrain, showing the tiny speck of calcification in the left basal ganglia.

with a greater risk of basal ganglia strokes [7].

How does such a trivial trauma predispose to strokes? One postulate is that shearing stresses across the mineralised lenticulostriate vessels may lead to a spasm of the vessel, leading to thrombotic occlusion1. In the literature so far, the reason for the predisposition of stroke in the infantile age group [8] and the follow-up evidence for persistently mineralised vessels as they grow up is not clearly defined.

This report is unique as it highlights the presence of hemorrhagic stroke following a trivial trauma, with an excellent recovery in a young child.

Vascular anomalies such as arterio-venous malformations are a differential, but was thoroughly ruled out by the digital subtraction angiographic study. Moreover,the follow-up images showed mineralisation along the lenticulostriate vessels. The presence of a single mineralised vessel, even in the opposite basal ganglia, further confirmed the diagnosis of mineralising angiopathy.

Around 20 children between seven months and 17 months with mineralising angiopathy were described recently [9]. In contrast, this study is a description of a hemorrhage in a young boy. A possible hypothesis could be that the cumulative dynamics of the ongoing mineralisation at a later age probably protect vessels from spasm and thrombus, preventing the shear stress and rupture of an inefficiently mineralised vessel after a trivial trauma. Traumatic dissection of the lenticulostriate vessels leading to hemorrhage could be another possibility [5].

\section{Conclusion}

Mineralising arteriopathy is a common etiology for ischemic strokes in children. This study highlights that it could even lead to haemorrhage. The patient described in the report was older and might offer a reason for the etiological subtype of this stroke in terms of pathogenesis and the vessel wall dynamics, which is different to the infarcts described so far. There is a need to further follow-up patients with incidental mineralising angiopathy beyond infancy, to establish 
a causal association.

\section{Competing interests}

The authors have declared that they have no competing interests.

\section{Author contributions}

All the authors contributed to and also critically reviewed the manuscript. The final version of the manuscript was approved by all the authors.

This is an Open Access article distributed under the terms of the Creative Commons Attribution License (http://creativecommons.org/licenses/by/4.0), which permits unrestricted use, distribution, and reproduction in any medium, provided the original work is properly credited. The Creative Commons Public Domain Dedication waiver (http://creativecommons.org/publicdomain/zero/1.0/) applies to the data made available in this article, unless otherwise stated.

Cite this article as:

Sireesha Y, Ali N, Neeharika M, Kanikannan MA. A rare case of hemorrhagic mineralising angiopathy after trivial head trauma. JICNA [Internet]. 2019Dec.19;1(1). Available from: https://jicna.org/index.php/journal/article/view/jicna-

2019-141

\section{References}

[1] Lingappa L, Varma RD, Siddaiahgari S, Konanki R. Mineralizing angiopathy with infantile basal ganglia stroke after minor trauma. Dev Med Child Neurol. 2014 Jan;56(1):78-84. PublMed.

[2] Okuno T, Takao T, Ito M, Konishi Y, Mikawa H, Nakano Y. Infarction of the internal capsule in children. J Comput Assist Tomogr. 1980 Dec;4(6):770-774. PublMed.

[3] Landi A, Marotta N, Mancarella C, Marruzzo D, Salvati M, Delfini R. Basal ganglia stroke due to mild head trauma in pediatric age - clinical and therapeutic management: a case report and 10 year literature review. Italian journal of pediatrics. 2011 jan;37:2. PublMed.

[4] Teele RL, Hernanz-Schulman M, Sotrel A. Echogenic vasculature in the basal ganglia of neonates: a sonographic sign of vasculopathy. Radiology. 1988 nov;169(2):423-7. PublMed.

[5] Ishihara C, Sawada K, Tateno A. Bilateral basal ganglia infarction after mild head trauma. Pediatrics international : official journal of the Japan Pediatric Society. 2009 dec;51(6):829-31. PublMed.
[6] Livingston JH, Stivaros S, Warren D, Crow YJ. Intracranial calcification in childhood: a review of aetiologies and recognizable phenotypes. Developmental medicine and child neurology. 2014 jul;56(7):612-26. PublMed.

[7] Chaw-Liang C. Clinical Significance of Lenticulostriate Vasculopathy. ARC Journal of Pediatrics. 2016;2(1):48.

[8] Sobani ZA, Ali A. Pediatric traumatic putamenal strokes: Mechanisms and prognosis. Surgical neurology international. 2011;2:51. PublMed.

[9] Goraya JS, Berry S, Saggar K, Ahluwalia A. Stroke After Minor Head Trauma in Infants and Young Children With Basal Ganglia Calcification: A Lenticulostriate Vasculopathy? Journal of child neurology. 2018;33(2):146152. PublMed. 